\title{
The Urban Design Methods of Future Community
}

\author{
Jin Li \\ School of Architecture and Urban Planning \\ Huazhong University of Science and Technology \\ Wuhan 430074, China \\ $\&$ \\ Central south university of forestry and technology \\ Changsha 410000, China \\ Mingshu Li \\ School of Architecture and Urban Planning \\ Huazhong University of Science and Technology \\ Wuhan 430074, China \\ E-mail: tonny168@126.com
}

\begin{abstract}
With the gradual enhancement of people's life level, their requirements about the residence quality are higher and higher, and the occurrence of the concept of community provides a new idea. Based on thus background, the connotation and characteristics of the future community are introduced in this article, and the basic methods of the community urban design are discussed.
\end{abstract}

Keywords: Future, Community, Urban design

\section{Connotation and characteristics of the future community}

\subsection{Connotation of the future community}

With the gradual enhancement of people's life level and the continual improvement of the residence condition, people have no longer satisfied the simple and superimposed residence mode, and the residence quality and connotation have been comprehensively enhanced and developed, so a new concept should be adopted to suit for the requirement of the social development. The concept of the community could provide a new idea to solve these social problems.

The community is the concept in the sociology, which means the group of the people who live in one special region to realize multiple targets, and it is an entity name coming of western civilization of human life. As a basic cell of the city, good community could form special identification, adscription, security, and emotion for residents in the community, and its formation involves various factors such as people, space, environment, economy, and culture. Therefore, the community has the dynamic and perfecting developing process, and it could fit for the requirements of the continual change and development of the society, with large life power.

\subsection{Characteristics of the future community}

\subsubsection{Complexity}

The complexity of the community could reflect that the community is a social synthesis which has the functions such as production and life, contains various activity factors such as material, culture, economy, and politics, and integrates different people from different ages, classes, occupations, cultures, and economic backgrounds. Therefore, the function of the community goes to diversification, and various suited requirements are very complex. What the community provides to people is not only materials, but large numerous of professional division to satisfy community members' various demands.

\subsubsection{Sustainability}

The sustainability of the community could fully embody the strong life source of the community. The sustainable community is the community construction mode with low dependence of the autos, harmonious coexistence with 
the ecological system, strong adscription sense and agglomeration force, and harmonious relationship. It contains three aspects.

(1) The community should keep the intergrowth relationship with the natural environment, and the natural landform, water system, and vegetation should be kept as more as possible in the community, being harmonious with the nature.

(2) The traffic system of the community should conveniently connected with the general traffic network, with more pedestrian streets and bicycle channels, and more establishments should be allocated in the space where people could walk to, and the road system should be allocated by the ends Lu calls or the grid form.

(3) The community should adopt more energy-saving technologies such as the water and energy saving measures, the careful road planning, the allocation of buildings, the utilization of sunshine and umbrage, the enhancement of the sun energy utilization, and the reusing of the wastes.

\subsubsection{Cultural characteristic}

"Same one region" is the most basic factor to form the community, and this concept is different with the district in the geography. The district is planned for the management of the government, and the geological boundary is very clear, but the community is formed naturally in the social life for a long term, and its geological boundary is very obscure.

Different communities have obviously different geological characteristics. In the material space formation of the city, different cities have different cultural heritages and backgrounds, even in same one city, the urban road network, building groups, and sight gardens are different in different stages.

Another factor of the community geological character is that the people on different layers would certainly produce different social cultures, and present different geological characteristics of the community. The difference and the diversity of different community cultures and backgrounds will induce different locale characteristics and life atmospheres, which would indicate special characters and humanistic spirit of the community.

\section{Basic methods of the community urban design}

The humanistic spirit in the community urban design determines the connotation of the community urban design, including the construction and allocation of the material factors, the people-oriented basic principle, the construction of humanistic and interactive community life mode and communication network through the using of the material carrier, the introduction of information service, economic consultation, and gym service into the community, and make the community with the balanced function of small-scale society.

Therefore, the basic content of the community urban design is to rebuild and perfect many factors such as people, region, environment, economy, and culture composing the community, and especially pay more attention to care about the special groups (old people, unemployment people, disabled people, and children), and create a new structure system of the community which could fulfill community members' individuation, diversification, and non-systematization.

According to the function requirement of the community urban design, the basic content of the community urban design includes five aspects, i.e. (1) bright geological space characteristic building, (2) high-effectively reasonable land utilization structure allocation, (3) perfect and convenient suited service establishment and mechanism, (4) optimized community environment quality, and (5) high-effective and environment-protected organic development resource allocation.

\subsection{Characteristic creation of brightly regional space}

The characteristics of the community urban design are presented in two aspects, and one is the material space formation characteristic, and the other one is the non-material cultural connotation characteristic. The material space formation includes the urban road network and the building allocation formed in various terms, and according to the characteristics, the material space formation can include the historical scene conservation district, the excellent building group, the culture ashes, the proficient' former residence, the important cultural establishments, the key urban public and opening spaces, which are all important factors of the personality and characteristic of the community, and could provide important material condition for the diversity of the community spatial organization.

The non-material cultural connotation characteristic is presented by the life habit and mode with geological characteristics formed by the regional cultural resource, i.e. the diversity and the different of the community culture, which are determined by the similarities and differences of people's cultural layers in the community. As 
viewed from the sociology, the community is composed by the groups from different backgrounds, and the groups on different layers certainly induce different community cultures, and embody different geological characteristics, and the centralized spots and social locales of different community cultures are the centralized embodiment of these cultures. The centralized spots in the old city may be in tea houses and street greenbelts, and the workers' centralized spots many be the cultural palace, and the intellectuals' centralized spots may be salons and tennis courts, and the minority and religion believers' centralized spots may be special locales. The difference of the cultural backgrounds indicates the geological characteristics, and certainly induces the diversity of the community culture.

\subsection{Reasonable and optimized land using allocation structure}

The land use of the community is different with the land use of past residence region, and the function and target of the community construction is mainly to satisfy various people's basic demands in this community, and these demands compose a complex comprehensive function, not a single function such as residence, sleep, and rest. Therefore, the land use structure of the community should be a comprehensive land classification, and multiple functions may be embodied in single one land at the same time, and the land use function allocation will not be entirely different.

(1) According to the geological characteristic of the community, the land use structure of the community could be confirmed, and according to the community planning and construction target and concrete situation, the land use proportion demands of different functions such as residence, commerce, culture, road, virescence, and municipal establishment should be distributed, and the land use construction contents which could embody the land use characteristics should be emphasized, and their composing proportions should be extended properly to provide material base for fulfilling individual groups' demands in the community.

(2) The lower limit of the non-building land use and the development space of the building land use in the community should be controlled to provide a basic guarantee for the sustainable development and the ecological environment of the community, and adapt the dynamic development of the community, and ensure the life and energy of the community.

(3) The proportion of the residence land use and the employment land use should be harmonized, which should not only keep certain residence land use to keep the energy of the community, but leave certain employment posts to balance the structure and avoid single community employment and economic structure.

(4) The land use proportion of the road and square in the community should be controlled reasonably, and the corresponding traffic and park establishments should be allocated, and the people's basic demand in the community should be fulfilled by reasonable traffic organization management and improvement of traffic conditions. The traffic organization should implement the form of "separation of people and vehicles" as far as possible to ensure the quality of the community life. This proportion should be controlled according to $25 \%$.

(5) The green coverage ratio should be enhanced comprehensively, and multiple green modes should be adopted to open various unit green lands in the community, ensure the green land proportion, and guarantee the life quality and the ecological quality of the community. The planning of the green system should be combined with people's behavior tracks according to local conditions.

\subsection{Establishing perfect and convenient community service establishment system}

The service function of the community should provide not only socialized services for employers in non-working time, but also all-directional services for non-employees. Concretely, the service establishment allocation of the community should fulfill people's three demands in the community, i.e. the modern demand of common people, which introduces the activities such as employment, leisure, and culture into the community, and the future demand of special people and normal people, especially, the pursuing of the life and environment quality should be the final target of the community service establishment allocation.

Therefore, when fulfilling the suited service demands such as culture, education, commerce, and sanitation, the community construction establishment content should fulfill special groups' service establishment and increase special service establishment contents such as gym leisure, employment, information, and reeducation. At the same time, the realty management center or the community committee should constitute various methods and mechanisms to use these establishments and high-effectively exert the functions of these establishments. Not only people's pursuing of daily life quality should be fulfilled, but the people who really need help should be satisfied. 


\subsection{Creating and optimizing the environment quality, and enhancing the harmoniously social network system}

The environment quality of the community includes two parts, one is the material ecological environment of the community, and the other one is the humanistic environment of the community. The material ecological environment includes the natural ecological resource and the man-made ecological resource. In the urban design of community, the special natural sights such as river, old trees, and temples should be conserved in the community, and they should be utilized, with proper green and public spaces, to form interesting environment sight quality. The man-made ecological sight generally means various building sights, and the building forms and colors in the community should be determined by the geological characteristics of the community, and accord with the basic taste of the total group in the community. The community urban design should emphasize the harmony and uniform of people and nature, and the organic integration of building and environment, green and square.

Based on the material ecological environment, a good communication locale is the important part to optimize the environment quality in the community. In the common geological space, people could understand and help each other, and participate in the activities of the community, the management of the community, and make the community become more safe and harmonious. To improve the social and cultural atmospheres is the effective approach to enhance the humanistic environment quality, and many measures such as science and technology, culture, and arts should organized to enhance the people's quality in the community, and reeducate and train the members of the community, and strengthen the peoples' proud sense of adscription, and correspondingly enahcne the environment quality of the community.

\subsection{Resource allocation of the future development of the community}

With the advancement and development of the society, especially the large change of the science and technology, the high and new technologies and new cultures certainly will be embodied in the community urban design, which could ensure the energy of the community construction, especially the social informationization will not only largely influence the function demand of the community, but largely impact the communication network system of the community, so in the community urban design, certain space resources should be kept for the future development, and relative designers should adopt effective corresponding measures to perfect the content of the community urban design, and provide an organically developed life space for the members of the community.

\section{References}

Liu, Rongzeng \& Cui, Gonghao. (2000). The Deviation and Unification of the Tool Rationality and the Value Rationality in the Community Planning. Urban Planning, No. 4.

Lv, Bing. (1993). Planning Concept and Practice of the Sustainable Community. Foreign Urban Planning, No. 3. 